SFB

Predatory short sales and 823 bailouts

Sebastian Kranz, Gunter Löffler,

Peter N. Posch

Nr. 23/2017

$\omega$

$\infty$

(

(1)

(D)

D

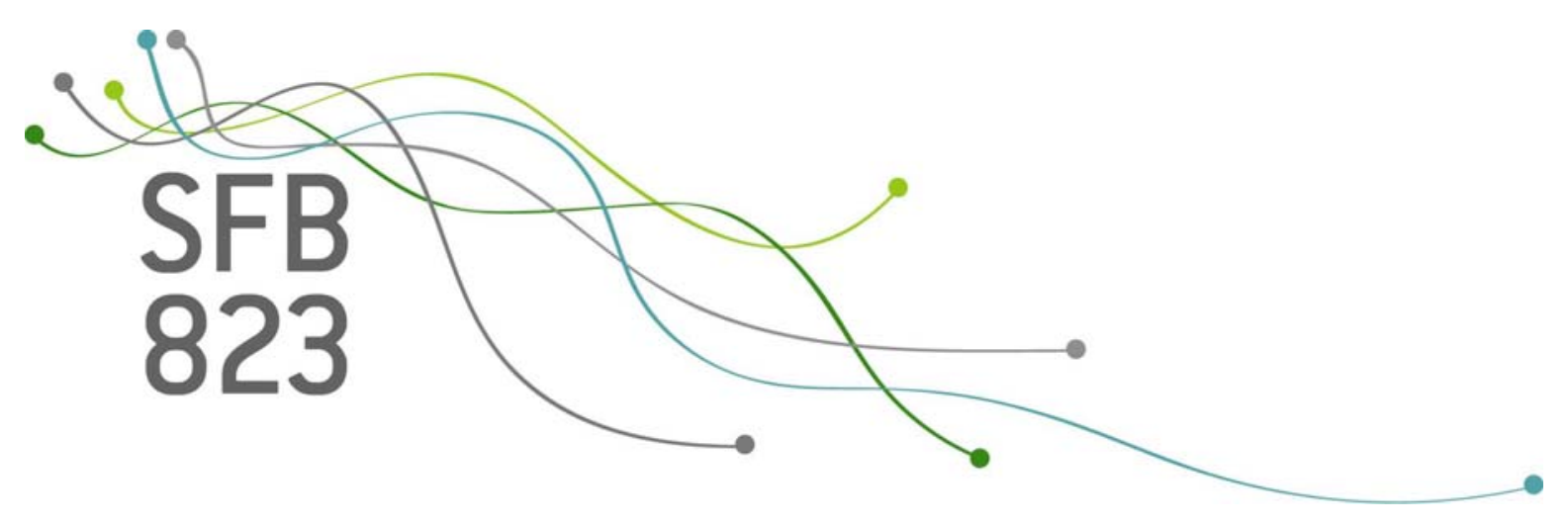





\title{
Predatory Short Sales and Bailouts
}

\author{
Sebastian Kranz, Gunter Löffler ${ }^{\dagger}$ and Peter N Posch ${ }^{\ddagger}$
}

December 1, 2017

\begin{abstract}
This paper extends the literature on predatory short selling and bailouts through a joint analysis of the two. We consider a model with informed short sales, as well as uninformed predatory short sales, which can trigger the inefficient liquidation of a firm. We obtain several novel results: A government commitment to bail out insolvent firms with positive probability can increase welfare because it selectively deters predatory short selling without hampering desirable informed short sales. Contrasting a common view, bailouts can be optimal ex ante but undesirable ex post. Furthermore, bailouts in our model are a better policy tool than short selling restrictions. Welfare gains from the bailout policy are unevenly distributed: shareholders gain while taxpayers lose. Bailout taxes allow ex-ante Pareto improvements.
\end{abstract}

Keywords: Government bailouts, short sales, predatory trading, short sale bans JEL-Classification: G01, G14, G28, G38, D53, D82

Acknowledgement: The author Peter N Posch acknowledges support by the Collaborative Research Center "Statistical modeling of nonlinear dynamic processes" (SFB 823) of the German Research Foundation (DFG).

*University of Ulm, Faculty of Mathematics and Economics, sebastian.kranz@uni-ulm.de †University of Ulm, Faculty of Mathematics and Economics, gunter.loeffler@uni-ulm.de

$\ddagger$ University of Dortmund, Faculty of Economics and Business, peter.posch@udo.edu. Corresponding author. 


\section{Introduction}

In a seminal paper Miller (1977) shows that short selling is crucial for market efficiency. If investors differ in their expectations, and short selling is not possible, prices do not aggregate the views of pessimists and optimists because the latter end up trading with themselves. In recent financial crises, this beneficial view of short sales has been challenged. A purported strategy is to depress market prices though aggressive short selling, hoping that this triggers a panic or value-destroying actions by the shorted company. Concerned about this possibility of predatory short selling, regulators around the world have temporarily banned short selling activities. ${ }^{1}$

Another policy instrument in recent crises was government bailouts. They came in various forms such as capital injections, cheap credit or asset purchases above market prices. One link between short selling and bailouts is that a firm that is put in distress by short selling may ask for a bailout. This papers highlights another effect: an ex-ante commitment to bailing out distressed firms with positive probability can make socially harmful short selling strategies less attractive without hampering desired short sales.

Specifically, we study a firm that needs to refinance its debt in order to complete a long-term investment project. A strategic trader either has superior negative information about the project and thus conducts desirable informed short sales, or the trader is uninformed but nevertheless considers a predatory short selling strategy. There is also a continuum of rational but uninformed competitive financial investors. As these investors cannot distinguish informed from uninformed short sales, the latter can be wrongly interpreted as a signal for a bad firm. In such a case, inefficient liquidation of an attractive project can lead to a decline in prices, which leaves the predatory short seller with a profit.

In this context, a commitment of the government to bail out a distressed firm with a positive probability can prevent predatory short sales while not reducing the frequency of informed short sales. Due to this deterrence effect, a positive bailout probability can increase the efficiency of financial markets as well as total welfare. A short sale ban, by

\footnotetext{
${ }^{1}$ The SEC, for example, motivated the 2008 short selling ban by stating: "Recent market conditions have made us concerned that short selling in the securities of a wider range of financial institutions may be causing sudden and excessive fluctuations of the prices of such securities in such a manner so as to threaten fair and orderly markets" (SEC 2008, p. 1)
} 
contrast, would prevent both informed and uninformed short selling, and is therefore inferior in the model that we study.

Our results are not only new because they shed light on the possible connections between short selling and bailouts. They also add new aspects to the understanding of bailouts.

First, we find a commitment problem that is opposite to the common commitment problem in the literature. Starting with Thornton $(1802)^{2}$ the literature highlights undesired effects of bailout policies on risk taking, and outlines strategies for dealing with the time inconsistency that can arise because a bailout may be welfare optimal ex post, but not necessarily ex ante (e.g. Mailath and Mester 1994, Acharya and Yorulmazer 2007, Farhi and Tirole, 2012, Bernardo, Talley and Welch, 2014, Chari and Kehoe, 2013). In our model, the ex-ante effect of bailouts is positive because they suppress predatory short sales. Ex post, the insolvency probability is so high that the government would always prefer not to bail out the firm.

Our model abstracts from exogenous externalities of bailouts for the sake of a clear exposition of the effects that are novel to the literature. Bailouts can have positive externalities if they help avoid negative feedback effects between banks (e.g. modeled in Philippon and Schnabl, 2011), improve creditor confidence (Cheng and Milbradt, 2012), or secure benefits that stakeholders derive from a continued existence of the firm (Bernardo, Talley and Welch, 2014). On the other hand, funding the bailouts can lead to costs in the form of tax-induced inefficiencies and higher sovereign credit risk (Bernardo, Talley and Welch, 2014, Acharya, Drechsler and Schnabl, 2011).

Even though we abstract from such exogenous externalities of bailouts, Bagehot's dictum that only solvent firms with good collateral should be bailed out does not hold in our model. ${ }^{3}$ If a welfare optimal bailout policy fully deters predatory short sales, remaining short sales are always informed and a bailout after a short sale always rescues an insolvent firm.

\footnotetext{
2 "It is by no means intended to imply, that it would become the Bank of England to relieve every distress which the rashness of country banks may bring upon them: the bank, by doing this, might encourage their improvidence" (Thornton, 1802, p.188).

3 "Advances should be made on all good banking securities" (Bagehot, 1873, ch. VII.II). An example for a policy reference to this dictum is Bernanke's (2008) statement on Lehman Brothers: "A publicsector solution for Lehman proved infeasible, as the firm could not post sufficient collateral to provide reasonable assurance that a loan from the Federal Reserve would be repaid."
} 
As in Goldstein and Guembel (2008), Brunnermeier and Oehmke (2014) and Liu (2010), aggressive shorting can be profitable because it triggers inefficient actions by the shorted company. These studies, which do not consider bailouts, find that short selling restrictions can be welfare increasing. In our model, a bailout policy dominates short sale restrictions because it selectively reduces predatory short sales while keeping informed short sellers in the market. Consistent with these results and the intense use of bailouts by governments, empirical studies on the financial crisis suggest that short selling during the financial crisis did not have a strong destabilizing impact (Bailey and Zheng, 2013) and that short sale restrictions largely failed to achieve the aim of stabilizing prices (cf. Beber and Pagano, 2013, and Boehmer, Jones, and Zhang, 2013).

Though much of the recent policy debate and many academic papers focus on financial institutions, we study a generic firm that could as well be an industrial or service firm. Direct support of non-financial firms is common. Examples in the US include loans to airlines in 2001, and to Chrysler and General Motors in 2008. International datasets compiled by Faccio, Masulis, and McConnell (2006) and Smith (2012) contain many bailouts of non-financial firms.

The remainder of the paper is organized as follows. The following section introduces the basic model. The third section discusses the effects and comparative statics of bailouts and short sales. The fourth section studies further aspects. We first discuss why a private commitment to refinance after a short sale is less efficient and credible to deter predatory short sales than a bailout policy. We then discuss incorporation of additional signals in the bailout decision and compare the bailout policy with a policy that simply forbids short sales. The fifth section briefly concludes.

\section{Interaction between investors and traders in the absence of bailouts}

This section develops and analyzes a basic model without bailouts. An overview of the model 's variables is given in the appendix. In a nutshell, we study a firm that can be a good or bad type, with all assets invested in a risky project. Majority shareholders are small, risk-neutral competitive investors that do not know the firm's type and must 
decide on premature liquidation of the project. There is a strategic trader, who learns with positive probability the firm's type and can trade in the stock market before the liquidation decision. In equilibrium, short sales are a noisy, informative signal about a bad firm type and can thus trigger liquidation. In a predatory short sale, the trader has no information that the firm is a bad type but still benefits due to the triggered liquidation.

\subsection{Firm and investment project}

There is a firm that has its entire assets invested in a risky project. The time line of the model is characterized by three dates $t_{1}, t_{2}$ and $t_{3}$ as illustrated in Figure 1.

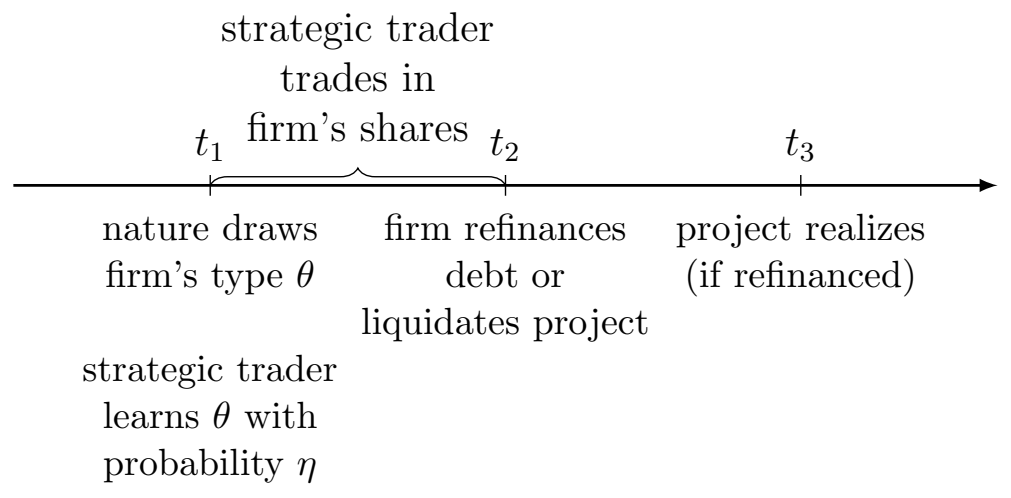

Figure 1: Time line of the model without bailouts

At $t_{1}$ nature draws the firm's type $\theta$, which can be good, $\theta=g$, or bad, $\theta=b$. The probability of a good type is given by

$$
\operatorname{Pr}(\theta=g)=\gamma
$$

The type determines the success probability $\sigma_{\theta}$ of the firm's investment project, with $\sigma_{g}>\sigma_{b}$. We denote by

$$
\sigma_{u}=\gamma \sigma_{g}+(1-\gamma) \sigma_{b}
$$

the expected success probability given that the firm's type is unknown. The the project's payoff realizes at $t_{3}$. 
The resulting valuation of the firm's assets is given by

$$
\begin{cases}v & \text { if the project is successful } \\ 0 & \text { if the project fails. }\end{cases}
$$

The firm is financed with equity and debt. Without loss of generality we normalize the number of publicly traded stocks to 1 . The firm must repay its debt in $t_{2}$. The repayment amount (including interest) is $\Delta$. We assume that the firm refinances its debt by raising $\Delta$ dollar of new short term debt maturing at $t_{3}$. We denote by $i$ the interest rate of this new debt. If the firm fails to refinance its debt, it cannot continue the risky project, which will then be prematurely liquidated. Liquidation shall yield a fixed liquidation value of $L$, which is independent of the firm's type. The decision to liquidate a firm shall be endogenously made by the shareholders in our model. Consequently, we assume that the liquidation value is high enough to pay back current creditors: $L>\Delta$. Otherwise, the details of the country's bankruptcy laws would be crucial for modeling the liquidation decision, e.g. if $L<\Delta$ bankruptcy laws may have required liquidation already before $t_{2}$. The shareholders' payoff in case of early liquidation is given by

$$
L-\Delta>0
$$

We assume that it is socially efficient to liquidate a bad firm, i.e.

$$
\sigma_{b} v<L
$$

This condition will make informed short sales that trigger liquidation of a bad firm type beneficial from a welfare perspective. On the other hand, it shall be efficient to refinance a firm whose type is unknown

$$
L<\sigma_{u} v
$$

This condition has the effect that a predatory short sale, which triggers liquidation even though the firm type is unknown, will reduce welfare. 


\subsection{Shareholders' decision to liquidate or refinance}

There is a competitive fringe of risk-neutral passive small investors. Some investors own the majority of the firm's stocks and others can refinance the firm's debt by buying bonds at $t_{2}$. Outside investment opportunities pay a risk-less interest rate of zero. In addition, there is a risk-neutral strategic trader, who is possibly informed about the firm's type and can trade the firm's stocks before $t_{2}$. The details of the trading model are relegated to the next subsection. Trading activities are observed by the passive investors, who will rationally update their beliefs about the firm's type.

We denote by $\tilde{\sigma}$ the passive shareholders' and bond investors' beliefs at date $t_{2}$ about the success probability of the firm's project. The interest rate $i$ received for the bond is implicitly determined by the condition that expected returns are zero for a competitive bond investor

$$
\tilde{\sigma}(1+i)=1
$$

We assume that passive shareholders hold the majority of the firm's stocks and decide in $t_{2}$ whether the project shall be liquidated or not. If the project is not liquidated, shareholders expect a payoff of

$$
\tilde{\sigma}(v-\Delta(1+i))=\tilde{\sigma} v-\Delta
$$

The shareholders strictly prefer liquidation over refinancing if and only if

$$
L-\Delta>\tilde{\sigma} v-\Delta
$$

This condition is equivalent to the simple condition that liquidation proceeds are larger than the expected value of the project

$$
L>\tilde{\sigma} v
$$




\section{$2.3 \quad$ Strategic Trader}

The strategic trader initially holds no shares of the firm. At time $t_{1}$ the firm's type (good or bad) is revealed to the strategic trader with a revelation probability $\eta$. With the complementary probability $1-\eta$ the trader has no better information than any competitive investor. Between $t_{1}$ and $t_{2}$, the strategic trader can trade the firm's shares in the market.

We describe trade activities in the stock market with a reduced form model. ${ }^{4}$ The strategic trader will be able to profit from an informational advantage over competitive investors. Yet, competitive investors do observe trade activities and use those stock market signals to rationally update their beliefs about the firm's type.

Formally, the strategic trader chooses a trading strategy $\tau \in\{s, 0, \ell\}$ where $\tau=s$ indicates that a fixed amount of stocks is sold (short position), $\tau=\ell$ that a fixed amount is bought (long position) and $\tau=0$ means that no trades take place. ${ }^{5}$

At time $t_{2}$ competitive investors have observed the trading strategy $\tau$ and rationally form their beliefs $\tilde{\sigma}$ about the firm's type and the corresponding expected returns of loans given to the firm. We denote by $p_{t}$ the stock price at time t. The stock price $p_{2}$ will be given by the firm's valuation from the perspective of a competitive investor as: ${ }^{6}$

$$
p_{2}(\tilde{\sigma})=\max \{\tilde{\sigma} v-\Delta, L-\Delta\}
$$

The stock price $p_{1}$ in the first period will depend on the probabilities with which a good or bad firm, respectively, will be liquidated in equilibrium:

$$
p_{1}=(1-\gamma)\left(\lambda_{b} L+\left(1-\lambda_{b}\right) \sigma_{b} v\right)+\gamma\left(\lambda_{g} L+\left(1-\lambda_{g}\right) \sigma_{g} v\right)-\Delta
$$

where $\lambda_{\theta}$ denotes the equilibrium probability with which a firm of type $\theta$ will be liquidated. The price that the strategic trader pays, if $\tau=\ell$, or receives, if $\tau=s$, between

\footnotetext{
${ }^{4}$ The model reflects essential features of dynamic models of market micro structure like Kyle (1985). We do not explicitly model the counterparties of the trade. There can be noise traders with liquidity needs, or as in Kyle, market makers that cannot perfectly distinguish between uninformed noise traders and informed traders.

${ }^{5} \mathrm{~A}$ discrete action space allows to avoid uninteresting technicalities in the game theoretic analysis that would otherwise arise from equilibrium refinements in our signaling game between strategic trader and passive investors and from characterizing mixed strategies on a continuous action space.

${ }^{6}$ Recall that we normalized the amount of stocks to one.
} 
$t_{1}$ and $t_{2}$ shall be given by

$$
p_{\tau}=\alpha p_{1}+(1-\alpha) p_{2}(\tilde{\sigma}(\tau))
$$

The parameter $\alpha \in(0,1 / 2)$ measures the trader's order management ability in the market. If $\alpha=0$ the trader lacks all ability and will not be able to buy below or sell above the resulting price level $p_{2}$. For $\alpha=1 / 2$, the trader achieves the mean of $p_{1}$ and $p_{2}$ as average price. The assumption $\alpha<1 / 2$ implies that the trader could not make profits from a scheme in which he first sells stocks short (pushing down the price) and afterward buys them back (pushing up the price back to the initial level).

\subsection{Equilibrium behavior}

An informed strategic trader will act on his superior information. Intuitively, he buys shares when the good type is revealed and sells shares if the firm is a bad type. Thus the uninformed investors rationally reduce their belief $\tilde{\sigma}$ about the firm's success probability when they observe a short sale. This also means the firm's interest rate $i$ for refinancing its debt goes up after a short sale. As a consequence, a short sale can induce uninformed shareholders to prematurely liquidate the project instead of refinancing it.

A premature liquidation causes the stock price to drop to $L-\Delta$, a level below the initial price $p_{1}$. This price drop is independent of the actual type of the firm. If the likelihood of premature liquidation is sufficiently high, short sales are profitable for an uninformed strategic trader who has no information that the project is bad. We call such short sales (socially inefficient) predatory short sales. One can think of uninformed strategic traders who perform predatory short sales to free-ride on the fact that passive investors cannot distinguish between informed and predatory short sales.

We will now formally develop these results. To exclude equilibria that are sustained by counter-intuitive out-of-equilibrium beliefs of passive investors, we make the following assumption.

Assumption 1. (Out-off equilibrium beliefs) Consider an equilibrium in which the probability that the strategic trader buys (short sells) shares is 0 . Then the out-off equilibrium event that the strategic trader buys (short sells) shares should neither 
1. reduce passive investors' belief that the trader was informed and knows that the firm type is good (bad), nor

2. increase passive investors' belief that the trader was informed and knows that the firm type is bad (good). Our first result is

Lemma 1. In every equilibrium the initial share price satisfies

$$
p_{1} \geq \sigma_{u} v-\Delta
$$

Proof. The risk-neutral passive investors who hold shares and make the liquidation decision in $t_{2}$ have a simple strategy that guarantees them an expected final payoff of $\sigma_{u} v-\Delta$ : they just never liquidate.

Lemma 1 is straightforward and holds since passive investors are perfectly rational and know the equilibrium strategies of the strategic trader. Therefore they cannot be systematically fooled into a liquidation strategy that leads to a lower expected value than the strategy to simply never liquidate the project.

The next result establishes that an informed trader who knows that the firm is a bad type will always perform short sales.

Lemma 2. In every equilibrium an informed trader always performs short sales $\tau=s$ if the revealed firm type is bad $\theta=b$.

Proof. If an informed trader who knows that the firm type is bad does not trade he makes zero profits and if he buys stocks, it follows from Lemma 1 that he makes losses in expectation. We now show that in every equilibrium an informed trader can guarantee strictly positive expected profits by short selling shares. A short sale is profitable if the expected resulting share price is below $p_{1}$. If the short sale leads to liquidation, the share price drops from $p_{1} \geq \sigma_{u} v-\Delta$ to $p_{2}=L-\Delta<\sigma_{u} v-\Delta$, which renders the short sale profitable. Alternatively, there is no liquidation after the short sale. For the informed trader the expected resulting stock price in $t_{3}$ is then given by

$$
\sigma_{b}(v-(1+i) \Delta) .
$$


The interest rate $i$ depends on passive shareholders' beliefs $\tilde{\sigma}$ about the success probability

$$
1+i=1 / \tilde{\sigma}
$$

To show that expected final share price will drop after a short sale, we must distinguish different cases.

i) Consider an equilibrium, in which short sales are only performed by an informed trader who knows that the firm is a bad type. Then a short sale reveals to passive investors that the firm is a bad type, such that $\tilde{\sigma}=\sigma_{b}$. Expected stock price in $t_{3}$ then simplifies to $\sigma_{b} v-\Delta$, which is strictly below the original price $p_{1}$.

ii) Consider an equilibrium, in which on the equilibrium path short sales take place with zero probability. Assumption 1 then guarantees that after an out-off-equilibrium short sale passive investors hold beliefs that satisfy $\tilde{\sigma} \leq \sigma_{u}$. This guarantees that a short sale will be profitable for the informed trader, since (15) satisfies

$$
\sigma_{b}(v-(1+i) \Delta) \leq \sigma_{b}\left(v-\frac{1}{\sigma_{u}} \Delta\right) \leq \sigma_{u} v-\Delta<p_{1}
$$

iii) Consider an equilibrium in which on the equilibrium path an uninformed strategic trader or an informed trader who knows that the firm type is good perform short sales with positive probability. These trader types must make non-negative expected profits from a short sale since they can reach a zero payoff by simply not trading. If a short sale always leads to liquidation, the short sale is always profitable, as pointed out above. If there is a positive probability that a short sale does not lead to liquidation, the expected final stock price is strictly lower for the informed trader who knows that the firm type is bad than for an uninformed strategic trader who performs short sales; hence the informed strategic trader must make strictly positive expected profits from the short sale in this case.

Non-surprisingly, an informed trader who knows that the firm type is good benefits from buying the firm's shares. However, it might even become profitable for an informed trader who knows that the firm is a good type to perform a short sale if that short sale triggers a liquidation with sufficiently high probability. There will never be an equilibrium in which a trader who knows that the firm is good always performs short 
sales, since then short sales would not be informative anymore and no liquidation would ever take place. Yet, in certain parameter ranges, we could have a mixed strategy equilibrium in which such a trader mixes between buying the stock and short selling it. To avoid tedious and uninteresting case distinctions, we will rule out this case in the subsequent analysis.

Assumption 2. We restrict attention to cases in which an informed trader who knows that the firm is a good type always buys shares in equilibrium.

Given this behavior of the strategic trader, it will never be rational for competitive investors to liquidate the project if no short sales are observed. But since short sales become an informative signal for a bad firm type, liquidation after short sales can become rational for the shareholders. Let $q$ be the probability that an uninformed trader performs a predatory short sale (we allow for mixed strategies). The higher the probability of predatory short sales $q$, the less likely it is that an observed short sale was conducted by an informed trader and the less likely is a bad firm type; thus, the less inclined will shareholders be to liquidate. We find the following result.

Lemma 3. For passive investors it will be (weakly) profitable to liquidate the project after having observed short sales if and only if the probability $q$ that uninformed traders perform predatory short sales is (weakly) below a critical level

$$
\bar{q} \equiv(1-\gamma) \frac{\eta}{(1-\eta)} \frac{\left(L-\sigma_{b} v\right)}{\left(\sigma_{u} v-L\right)}>0
$$

Proof. Let $q$ be the probability that an uninformed strategic trader performs predatory short sales. A predatory short sale then happens with probability $(1-\eta) q$ while an informed short sale happens with probability $(1-\gamma) \eta$. Hence, after observing a shortsale passive investors' rational beliefs about the project's success probability are given by

$$
\tilde{\sigma}(s \mid q)=\frac{(1-\eta) q \sigma_{u}+(1-\gamma) \eta \sigma_{b}}{(1-\eta) q+(1-\gamma) \eta}
$$

Passive shareholders will weakly prefer liquidation after short sales if and only if $\tilde{\sigma}(s \mid q) v \leq$ $L$, which is equivalent to 


$$
q \leq \bar{q} \equiv(1-\gamma) \frac{\eta}{(1-\eta)} \frac{\left(L-\sigma_{b} v\right)}{\left(\sigma_{u} v-L\right)}
$$

If $\bar{q}>1$ the shareholders will always prefer to liquidate the behavior after a short sale, independent of the frequency of short sales by an uninformed strategic trader. We will restrict attention to this case in our subsequent analysis.

Assumption 3. Henceforth, we assume $\bar{q}>1$, i.e. after short sales passive shareholders always prefer to liquidate the project.

Given that short sales always trigger liquidation after a short sale the share price drops to

$$
p_{2}(s)=L-\Delta<\sigma_{u} v-\Delta<p_{1}
$$

and the predatory short seller always benefits from the short sale. We thus find for our basic model without bailouts the following result:

Proposition 1. Absent bailouts and given $\bar{q}>1$ an uninformed strategic trader will always perform a predatory short sale, and every short sale triggers a liquidation of the project.

\section{$3 \quad$ Bailouts and short sales}

\subsection{Overview of bailouts}

We now study the effects of a bailout policy on the prevalence of predatory and informed short sales and on total welfare. We consider bailouts of the following form: in case that refinancing conditions for a firm are so expensive that it chooses to liquidate the project, the government can offer a cheaper loan that prevents this liquidation (debt bailout). In this section, we assume that the government has the same information as passive investors, i.e. it has no superior information about the firm's type.

We consider bailouts in which the government pays not more for the bailout than is necessary to prevent liquidation. This means the bailout loan is given at an interest 
rate $i^{*}$ such that the shareholders are indifferent between refinancing and liquidating, i.e.

$$
\tilde{\sigma}(s)\left(v-\Delta\left(1+i^{*}\right)\right)=L-\Delta .
$$

As will become evident from the analysis below, $i^{*}$ is the lowest interest rate that still guarantees that an informed short seller will not be harmed by a bailout.

We assume that the government can commit ex ante to a bailout policy that triggers a bailout with a fixed probability $\beta \in[0,1]$ if absent bailouts the project were liquidated. The assumption that bailouts are decided purely randomly allows us to cleanly show how a positive bailout probability can be efficient, even absent any superior information by the government. In Section 4, we will discuss the case in which the government receives a private signal about the firm's type before the bailout decision. Instead of randomizing, it will then be optimal to perform bailouts for those firms whose signal indicates a higher likelihood of a good project.

The key reason why such bailouts can act as a screening device that selectively deter predatory short sales is that they affect expected profits of informed and uninformed short sellers in a different direction. An informed short seller knows that the firm is a bad type for which liquidation would be efficient. By preventing the efficient liquidation, the bailout even reduces resulting share prices. In contrast, given the lack of information of an predatory short seller, the expected firm value after the bailout is larger than its liquidation value. Therefore, by preventing an inefficient liquidation a bailout reduces profits of a predatory short seller.

\subsection{Ex-post effect of bailouts}

Consider the situation that after a short sale, a bailout is decided in $t_{2}$. While passive investors and the government believe the success probability of the firm to be $\tilde{\sigma}(s)$, an informed short seller knows that the success probability is $\sigma_{b}$ and an uninformed predatory short seller knows that the expected success probability is $\sigma_{u}$. Since an informed trader performs a short sale if and only if he knows that the firm is a bad 
type, we have

$$
\sigma_{b} \leq \tilde{\sigma}(s)<\sigma_{u}
$$

For the subsequent analysis, we use the index $\kappa \in\{u, b\}$ to denote a short seller's type, characterized by his knowledge about the firm: we have $\kappa=u$ for an uninformed predatory short seller and $\kappa=b$ for an informed short seller. After a bailout has been decided in $t_{2}$, a short seller of type $\kappa$ has the following expectation about the resulting share price in $p_{3}$ :

$$
\begin{aligned}
\bar{p}_{3}(\kappa) & =\sigma_{\kappa}\left(v-\left(1+i^{*}\right) \Delta\right) \\
& =\frac{\sigma_{\kappa}}{\tilde{\sigma}(s)}(L-\Delta)
\end{aligned}
$$

where we find the second line by plugging in condition (22) for the bailout interest rate $i^{*}$. Using this condition and (23), we also find

$$
\bar{p}_{3}(b) \leq L-\Delta<\bar{p}_{3}(u)
$$

This means a bailout weakly benefits an informed short seller, since expected resulting share prices in $t_{3}$ fall below the share price under liquidation. Given that the success probability is $\sigma_{b}$, a bailout lets a bad firm survive for one period longer and thereby destroys shareholders' value compared to an immediate liquidation. On the other hand, a bailout reduces profits, possibly leading to losses, for an uninformed predatory short seller, since, given his knowledge, the bailout raises expected share prices above the share price under liquidation. We summarize this result in

Lemma 4. Ceteris paribus, a bailout in period 2 weakly increases the expected profits of an informed short seller, but strictly reduces expected profits of an uninformed predatory short seller.

Proof. See derivation above.

\subsection{Bailout policy that deters predatory short sales}

We now study how a commitment to a bailout probability $\beta$ affects ex-ante profits and equilibrium behavior of short sellers. A short seller's ex-ante expected profit per share 
is given by

$$
\left.\bar{\pi}_{\kappa}(\beta)=p_{s}(\beta)-\left(\beta \bar{p}_{3}(\kappa)\right)+(1-\beta)(L-\Delta)\right)
$$

where $p_{s}(\beta)$ is the share price he receives in his short sales between period 1 and 2 and the term in brackets is the expected price at which he can buy back the shares. Since we assumed that $\bar{q}>1$, passive shareholders always want to liquidate the project after they observe short sales. If a bailout takes place, the interest rate $i^{*}$ makes these shareholders indifferent between liquidating or not, i.e. independent of a bailout taking place or not, the share price in period 2 after a short sale is $p_{2}(s)=L-\Delta$. A short seller thus gets the following average price when selling her shares between period 1 and 2

$$
p_{s}(\beta)=\alpha p_{1}(\beta)+(1-\alpha)(L-\Delta) \text {. }
$$

The initial share price is given by the expected value of the finally resulting share price

$$
\begin{array}{rlr}
p_{1}(\beta)= & (1-\eta) \cdot(1-q(\beta)) \cdot\left(\sigma_{u} v-\Delta\right)+ & \text { (uninformed trader who does not trade) } \\
& (1-\eta) \cdot q(\beta) \cdot(L-\Delta)+ & \text { (predatory short sale) } \\
& \eta \cdot(1-\gamma) \cdot(L-\Delta)+ & \text { (informed short sale) } \\
& \eta \cdot \gamma \cdot\left(\sigma_{g} v-\Delta\right), & \text { (informed trader goes long) }
\end{array}
$$

where $q(\beta)$ shall denote the equilibrium probability with which an uninformed trader performs a predatory short sale. Note that the bailout probability $\beta$ affects the initial share price only by its effect on the frequency $q(\beta)$ of predatory short sales. There is no direct effect of $\beta$ on the initial share price, because after a short sale passive shareholders are indifferent between a bailout or not.

An explicit characterization of $q(\beta)$ and the implied share prices, profits and welfare for all $\beta$ turns out to be fairly complex and becomes quickly intractable. We therefore restrict attention to characterizing a minimal bailout probability $\bar{\beta}$ that fully deters predatory short sales and we will compare such a deterrence policy with a no bailout policy.

We first note some preliminary results. 
Lemma 5. Consider an exogenous decrease in the frequency of predatory short sales $q$ (keeping the bailout probability $\beta$ and everything else constant). Then expected profits $\bar{\pi}_{\kappa}$ of both informed and predatory short sellers increase.

Proof. Follows directly from the equations above. In particular, we see from (28) observe that the initial share price $p_{1}$ is decreasing in $q$.

The intuition why expected profits of short sellers go up if the frequency of predatory short sales goes down is simple. A reduction of predatory short sales increases the initial firm value $p_{1}$, since fewer inefficient liquidations take place. This allows short sellers to sell the shares at a higher price. Furthermore, the expected price at which they have to buy back the shares is unaffected by the probability of short sales.

For the bailout probability $\beta$, we find

Lemma 6. An increase in the bailout probability $\beta$ (weakly) reduces the frequency $q(\beta)$ of predatory short sales and the expected profits $\bar{\pi}_{u}(\beta)$ of predatory short sales and (weakly) increases the expected profits $\bar{\pi}_{b}(\beta)$ of informed short-sellers.

Proof. Follows directly from the arguments leading to Lemma 4 and Lemma 5.

In an equilibrium in which predatory short sales are fully deterred, the initial share price will be given by

$$
\begin{aligned}
& p_{1}^{d}=(1-\eta) \cdot\left(\sigma_{u} v-\Delta\right)+\quad \text { (uninformed trader who does not trade) } \\
& \eta \cdot(1-\gamma) \cdot(L-\Delta)+\quad \text { (informed short sale) } \\
& \eta \cdot \gamma \cdot\left(\sigma_{g} v-\Delta\right) . \quad \text { (informed trader goes long) }
\end{aligned}
$$

The minimal bailout probability $\bar{\beta}$ required to deter predatory short sales will depend in a simple fashion on two markups. First, we have the relative markup of the initial share price compared to the period 2 price after a short sale:

$$
m_{12}=\frac{p_{1}^{d}-p_{2}(s)}{p_{2}(s)}=\frac{p_{1}^{d}-(L-\Delta)}{L-\Delta}
$$


A higher markup $m_{12}$, will make short sales more profitable and therefore requires a higher bailout probability to deter predatory short sales. Second, we have the relative markup of a predatory short seller's expected period 3 price over the expected period 3 price of an informed short seller given a bailout:

$$
m_{u b}=\frac{\bar{p}_{3}(u)-\bar{p}_{3}(b)}{\bar{p}_{3}(b)}=\frac{\sigma_{u}-\sigma_{b}}{\sigma_{b}}
$$

Intuitively, a higher markup $m_{u b}$ means that a predatory short seller loses more money when he has to buy back the shares in period 3 after a bailout; the required bailout probability to deter predatory short sales will then be lower.

Proposition 2. If the government commits to a bailout probability weakly above the critical level of

$$
\bar{\beta}=\alpha \frac{m_{12}}{m_{u b}}
$$

then in every equilibrium predatory short sales are fully deterred while the frequency of informed short sales is not affected by the bailout policy. For any bailout probability below $\bar{\beta}$ predatory short sales occur with positive probability in equilibrium.

Proof. Assume that for a given bailout probability $\beta$ all predatory short sales are deterred, i.e. no uninformed trader performs a short sale. We analyze for which $\beta$ uninformed traders make indeed no positive profits from a deviation to a predatory short sale. Straightforward algebra shows that the expected resulting share price at which an uninformed short-seller must buy back the shares can be written as

$$
\begin{aligned}
\beta \bar{p}_{3}(u)+(1-\beta)(L-\Delta) & \left.=\beta\left(\frac{\sigma_{u}}{\sigma_{b}}(L-\Delta)\right)+(1-\beta)(L-\Delta)\right) \\
& =\left(1+\beta m_{u b}\right)(L-\Delta)
\end{aligned}
$$

A predatory short seller's ex-ante expected profits per share, given that no predatory short sales take place in equilibrium, can then be written as

$$
\begin{aligned}
\pi_{u}^{d} & =\left[\alpha p_{1}^{d}+(1-\alpha)(L-\Delta)\right]-\left(1+\beta m_{u b}\right)(L-\Delta) \\
& =\alpha p_{1}^{d}-\left(\alpha+\beta m_{u b}\right)(L-\Delta)
\end{aligned}
$$


We see that these deviation profits are strictly decreasing in he bailout probability $\beta$. Setting $\pi_{u}^{d}$ equal to zero and solving for $\beta$, yields the critical bailout probability of

$$
\bar{\beta}=\alpha\left(\frac{p_{1}^{d}-(L-\Delta)}{L-\Delta}\right) / m_{u b}=\alpha \frac{m_{12}}{m_{u b}} .
$$

It follows from the monotonicity results in Lemma 5 and Lemma 6 that for $\beta>\bar{\beta}$ predatory short sales are deterred in all equilibria, while for $\beta<\bar{\beta}$ there can be no equilibrium in which predatory short sales are fully deterred.

Note that it is not always possible to fully deter predatory short sales with a positive bailout probability, since in certain parameter constellations, we can have $\bar{\beta}>1$. On the other hand, it is evident that for sufficiently small ability in order management $\alpha$, it is always possible to deter predatory short sales. The following result summarizes the comparative statics of the critical bailout probability.

Proposition 3. Ceteris paribus, the minimal bailout probability $\bar{\beta}$ to fully deter predatory short sales is decreasing in the liquidation value $L$ and increasing in the trader's ability of order management $\alpha$, the probability $\gamma$ that the firm is a good type and the probability $\eta$ that the strategic trader is informed.

Proof. Since $\alpha$ does not affect $m_{12}$ and $m_{u b}$, we simply have $\frac{\partial \bar{\beta}}{\partial \alpha}=\frac{m_{12}}{m_{u b}}>0$. The parameters $\gamma$ and $\eta$ only affect the critical bailout probability $\bar{\beta}$ via their effect on the initial share price $p_{1}^{d}$ absent predatory short sales, which satisfies $\partial \bar{\beta} / \partial p_{1}^{d}>0$. As can be easily verified from (29), this initial share price increases for a higher probability $\gamma$ that the firm is good or a higher probability $\eta$ that the informed trader is informed: $\partial p_{1}^{d} / \partial \gamma>0$ and $\partial p_{1}^{d} / \partial \eta>0$. That $\partial \bar{\beta} / \partial L<0$, follows from the fact that the markup $m_{12}$ is decreasing in the liquidation value $L$. This can be most cleanly seen by rewriting

$$
\begin{aligned}
m_{12} & =\frac{p_{1}^{d}-(L-\Delta)}{L-\Delta} \\
& =\frac{(1-\eta) \cdot\left(\sigma_{u} v-\Delta\right)+\eta \cdot \gamma \cdot\left(\sigma_{g} v-\Delta\right)}{L-\Delta}-(1-\eta \cdot(1-\gamma))
\end{aligned}
$$

and noting that the first term is positive and thus strictly decreasing in $L$. 


\subsection{Welfare}

While predatory short sales can be fully deterred by a bailout probability of $\bar{\beta}$, it is not obvious whether such a bailout policy is desirable from a welfare perspective. This section analyses the welfare effects of such a bailout policy. For a clean exposition, we want to abstract from shadow costs of government funds, which would make bailouts less attractive, and from exogenous positive externalities of bailouts, which would make them more attractive. Neither shall the distribution of expected payoffs among traders, passive shareholders, creditors and taxpayers affect our welfare measure. Consequently, we use the expected total payoff of the firm's project (accounting for the possibility of early liquidation) as welfare measure.

The welfare effect from changing a no-bailout policy to a bailout probability of $\bar{\beta}$, which fully deters predatory short sales, is given as follows:

$$
\begin{aligned}
W^{d}-W^{0} & =-\bar{\beta} \eta(1-\gamma)\left(L-\sigma_{b} v\right) \\
& +(1-\eta)\left(\sigma_{u} v-L\right)
\end{aligned}
$$

The first term (I) describes the classical negative effect of the bailouts: prevention of efficient liquidation. Absent bailouts, informative short sales, which happen with probability $(1-\gamma) \eta$, trigger efficient liquidation of a bad project. A bailout prevents this efficient liquidation, which causes a welfare loss of $L-\sigma_{b} v$.

The second term (II) describes the positive welfare effect of (ex-ante) deterrence of predatory short sales. Under a no-bailout policy, a predatory short sale takes place with probability $(1-\eta)$ and the resulting inefficient liquidation yields an expected welfare loss of $\sigma_{u} v-L$. This inefficiency is fully removed by a bailout policy that deters predatory short sales.

Comparing the negative and positive effect, we can establish the following result:

Proposition 4. There exists a critical ability in order management $\bar{\alpha}>0$ such that for all $\alpha<\bar{\alpha}$ a fully deterring predatory short sales with a commitment to a bailout probability $\bar{\beta}$ strictly increases welfare compared to a no bailout policy.

Proof. If $\alpha$ goes to zero, the critical bailout probability $\bar{\beta}$ needed to fully deter predatory short sales also goes to zero. This means also the negative welfare effect that predatory 
short sales prevent efficient liquidation goes to zero. In comparison, the positive effect from deterring predatory short sales is independent of $\alpha$. This means for sufficiently small $\alpha$ the positive effect outweighs the negative effect.

\subsection{Distribution of the welfare gains}

\subsubsection{Taxpayers lose, shareholders gain}

The following result shows the distribution of welfare gains and welfare losses when the government commits to a bailout probability of $\beta$ compared to the absence of bailouts.

Proposition 5. Assume in an initial period the government moves from a no-bailout policy to a welfare improving commitment to bailout with probability $\bar{\beta}$. This policy change leaves expected profits of the firm's creditors unaffected. It causes expected losses for the government, and shareholders make a gain equal to the sum of the total welfare gain and the absolute value of the government's losses.

Proof. We first note that creditors are in our model not affected by the bailout probability. The existing creditors get their loan repaid no matter whether there is a bailout or liquidation. If new creditors refinance loans at $t_{1}$ they always make zero expected profits and are therefore also indifferent.

Under a bailout probability $\bar{\beta}$ only informative short sales exist and thus any bailedout firm will have a bad project. Hence, given the government charges the highest interest rate $i^{*}$ that makes shareholders accept the bailout instead of liquidating, the government loses in expectation $L-\sigma_{b} v$ in a bailout and ex-ante expected losses are $(1-\gamma) \eta \bar{\beta}\left(L-\sigma_{b} v\right)$.

If there are no bailouts, we can rewrite equation (28) such that the initial stock market value of the firm (given $\bar{q} \geq 1$ ) is given by the following expected final payoff to the shareholders:

$$
p_{1}(\beta=0)=\sigma_{u} v-\Delta+(1-\gamma) \eta\left(L-\sigma_{b} v\right)-(1-\eta)\left(\sigma_{u} v-L\right)
$$

The first term $\sigma_{u} v-\Delta$ is the expected payoff to the shareholders if there is no strategic trading and hence no liquidation. The second term $(1-\gamma) \eta\left(L-\sigma_{b} v\right)$ is the expected 
positive impact of informed short sales that cause efficient premature liquidation. The last term is the expected welfare loss due to inefficient liquidation triggered by predatory short sales.

If the government commits to a bailout probability $\bar{\beta}$, the losses $-(1-\eta)\left(\sigma_{u} v-L\right)$ from predatory short sales vanish. Since a bailout takes place at the interest rate $i^{*}$ that makes shareholders indifferent between accepting the bailout or liquidating, the initial stock market value of the firm simply becomes

$$
\sigma_{u} v-\Delta+(1-\gamma) \eta\left(L-\sigma_{b} v\right)
$$

This means even though some of the bad projects after a short sale are bailed out instead of being liquidated, the shareholders have the same expected profits, as if there was always liquidation after an informed short sale. The expected ex-post inefficiencies from the bailouts $(1-\gamma) \eta \beta\left(L-\sigma_{b} v\right)$ are solely borne by the government.

If predatory short sales are fully deterred, only bad firms will be bailed out and the government will always make losses from its bailouts: The expected value of a bailed-out firm is just $\sigma_{b} v$, which is below the liquidation value $L$. Since the highest interest rate $i^{*}$ at which shareholders accept the bailout makes them indifferent between liquidation or not, these ex-post welfare losses of the bailout are fully borne by the government. In contrast, the ex-ante welfare gains from the new bailout policy are fully captured by the shareholders: the initial equity value $\left(p_{1}\right)$ increases since there is no more inefficient premature liquidation caused by predatory short sales. The shareholders' value increases by the total welfare gain plus the absolute value of the expected ex-post losses from bailouts borne by the government.

Given that shareholders gain more than the total welfare increase from a commitment to a positive bailout probability, there is scope for redistribution to achieve Paretoimprovements among taxpayers and shareholders without hurting creditors. Two policy instruments for this task are forced bailouts and bailout taxes for shareholders.

Corollary 1. Consider the case that a commitment to a bailout probability $\bar{\beta}$ increases total welfare compared to a no-bailout policies. Shareholders still benefit from such a policy change if the government in addition either 
1. decides that shareholders will be forced to accept government bailouts at the interest rate at which the government makes zero losses, even though the shareholders would have preferred to liquidate the project, or

2. imposes an ex-ante bailout tax on the firms such that the government's expected losses from bailouts are covered.

Similar policy instruments are indeed discussed and applied for banks. Forced recapitalizations of banks were discussed and de facto imposed by several countries during the financial crisis. In the European Union a common resolution fund for insolvent banks is planned for 2016. It will be financed by a bank levy, which can be considered as a form of bailout tax.

\subsubsection{Bailouts make informed short sales more profitable}

Uninformed strategic traders lose their profits from predatory short sales when the government commits to a bailout probability of $\bar{\beta}$. Yet, if it is welfare optimal to deter predatory short sales, informed short sales will become more profitable if the government commits to a bailout probability $\bar{\beta}$. That is for two reasons. First, given $\bar{\beta}$, short sales reveal a bad firm type. Therefore bailouts after a short sale do not increase the resulting stock price of a firm but reduces it from the value $L-\Delta$ under liquidation to an expected value of $\sigma_{b} v-\Delta$. This reduction benefits an informed short seller. Second, if it is welfare optimal to bail out with probability $\bar{\beta}$, the firm's ex-ante value and stock price $p_{1}$ increase when implementing $\bar{\beta}$. Hence, the informed short seller gets a higher price when originally selling the shares. Both effects increase expected profits of an informed short seller. We summarize these observations in

Corollary 2. Changing a zero bailout probability to $\bar{\beta}$ increases expected profits of informed short sales (while predatory short sales become unprofitable).

While not formally modeled in our framework, this suggests that strategic traders would have more incentives to spend money to investigate whether a firm has a bad type. This could be another channel how a higher bailout probability increases the informational efficiency of short sales in financial markets. 


\section{Discussion and Extensions}

\subsection{Commitment of shareholders to refinance after a short sale}

Similar to a commitment strategy noted in Goldstein and Guembel (2008), a firm could also deter predatory short sales if it could commit itself to refinance the project after a short sale at the market interest rate with positive probability. One could therefore question the need for government intervention. We focus on bailouts for the following two reasons.

Compared to a bailout at interest rate $i^{*}$ the expected share price after private refinancing at the market interest rate $i$ is lower by $\sigma_{u}\left(i-i^{*}\right) \Delta$. The larger is the debt level $\Delta$, the larger is the excess cost of private refinancing over a bailout. Hence, from the perspective of a predatory short seller, private refinancing is less harmful than a bailout because it does not increase the expected period 3 share price by as much. To prevent predatory short sales, the probability to privately refinance after a short sale would have to be strictly above the critical bailout probability $\bar{\beta}$. Since refinancing after a short sale is ex-post inefficient, a commitment to privately refinance the project is thus less efficient from a social perspective than an optimal bailout policy.

Second, the credibility of a private commitment to refinance after a short sale is an issue. While credibility could arise from repeated interactions, a single firm may not expect to be a repeated target of predatory short sales. Building up reputation for refinancing may therefore not be very valuable for a single firm. In contrast, the government may have much stronger incentives to build up reputation. Since many firms could potentially be the target of predatory short sales, the continuation game is much more relevant. More importantly, positive externalities from bailouts may weaken or even reverse the commitment problem for the government. We discuss this point in the next subsection.

\subsection{The reversed commitment problem of the government}

A common theme in the literature on bailouts is the following time-inconsistency problem: In good times, governments and central banks do not want to create expectations that they will bail out firms that get in distress. Such expectations could lead to 
moral hazard behavior, in the form of low managerial effort, excessive risk-taking or the choice of highly correlated strategies (cf. Acharya and Yorulmazer 2007, Farhi and Tirole, 2012, Bernardo, Talley and Welch, 2014, Chari and Kehoe, 2013). Once firms are in distress, however, negative external effects of firm closures or gains from rescuing illiquid but solvent firms can make bailouts attractive from a welfare perspective. In consequence, a commitment to a non-bailout policy may not be credible.

In this paper, we obtain the reverse. Raising bailout expectations is welfare-optimal because it deters predatory short selling; the eventual bailout reduces welfare because there are no externalities in our model, and distressed firms in equilibrium are always of bad type and insolvent. The latter also modifies Bagehot's dictum that only insolvent firms should not be bailed out. We obtain that they should, even though it appears to be inefficient ex post. In the literature on bailouts, Cordella and Yeyati (2003) is the only paper that arrives at a similar conclusion. In their model, bailout expectations increase the charter value of banks, which counterbalances the effects of risk-taking incentives.

\subsection{Using noisy information about the firm's type}

When the government can perform an investigation about the firm's type and receive a private signal, it is no longer optimal to perform bailouts randomly. Assume the government observes a noisy signal $y \in \mathbb{R}$ about the firm's type with density function $f(y \mid \theta)$. We assume that higher values of $y$ are more likely for a good type, formally the likelihood ratio $f(y \mid \theta=g) / f(y \mid \theta=b)$ shall be strictly increasing in $y$. It is then preferable from an ex-post perspective to perform bailouts after a high signal rather than after a low signal. Furthermore, higher signals are more likely after a predatory short sale (after which the firm may be a good or bad type) than after an informed short sale (after which the firm is always a bad type). This means a policy that performs bailouts after sufficiently high signals is also better able to deter predatory short sales ex ante than a random bailout policy. We summarize this result in

Proposition 6. If the government receives a continuously distributed private noisy signal $y$, with larger signals being more likely for good firms, a policy of random bailouts is dominated by a policy to perform a bailout if and only if $y \geq \bar{y}$ for some cut-off level 
Proof. Straightforward, see discussion above.

This result is more in line with Bagehot's dictum to only bail out solvent firms.

\subsection{Short sales ban}

Finally, we compare a short sale ban with bailouts in our model. A short sale ban means that the strategic trader has only the option to buy shares or to perform no trade. As in our basic model, it is optimal to buy shares if and only if the trader is informed about a good firm type. Given that no stock trades are observed under a short sale ban, passive financial investors' rational belief about the firm's success probability is given by

$$
\tilde{\sigma}_{0}=\frac{\eta(1-\gamma) \sigma_{b}+(1-\eta) \sigma_{u}}{\eta(1-\gamma)+(1-\eta)}
$$

If $\tilde{\sigma}_{0} v>L$, a short sale ban causes the project to be always refinanced no matter whether the strategic trader buys stocks or not. The short sale ban then yields the same total welfare as a bailout policy with a $100 \%$ bailout probability. The total welfare is

thus strictly lower than under a bailout policy with the bailout probability $\bar{\beta}<1$ that suffices to completely deter predatory short sales.

If $\tilde{\sigma}_{0} v<L$, passive investors prefer to liquidate the project if they do not observe that the strategic trader has bought stocks. Intuitively, the absence of good news from the stock market is now interpreted as sufficiently bad news about the firm's type to trigger liquidation. Hence, the short sale ban leads to the same outcome as if in the basic model without bailouts: an uninformed strategic trader always performs predatory short sales. This means in the case $\bar{q}<1$, the short sale ban, somewhat paradoxically, even increases the frequency of liquidations and reduces the total welfare compared to the baseline case with short sales and without bailouts. If $\bar{q}=1$ the short sale ban leads to exactly the same outcome as in the basic model without bailouts.

Overall, an optimal bailout policy dominates short sale bans because it allows to selectively reduce predatory short sales while keeping informed short sellers in the market. 


\section{Conclusion}

This paper extends the literature on predatory short selling and bailouts through a joint analysis of the two. We obtain several novel results: Bailing out insolvent firms can increase welfare because it makes uninformed short selling less attractive. Bailouts can thus be optimal ex ante but undesirable ex post. This complements the literature, which focuses on dealing with undesirable ex-ante effects (e.g. Farhi and Tirole 2012, Bernardo, Talley and Welch, 2014, Chari and Kehoe, 2013). Second, in our model bailouts are a better policy tool than short selling restrictions. This augments theoretical results on the optimality of short sale restrictions obtained by Goldstein and Gümbel (2008), Brunnermeier and Oehmke (2014) and Liu (2010). Finally, welfare gains are unevenly distributed: shareholders gain while taxpayers lose, which contributes to the debate over the redistribution effects of bailouts (e.g. Acharya et al. 2011).

To focus our analysis, we have abstracted from externalities of bailouts and from the fact that bailouts can induce moral hazard in form of excessive risk taking. Modeling these important factors can clearly modify the overall assessment of bailouts. Bailouts can turn out to be unattractive if the net effect of externalities and moral hazard is negative and stronger than the positive effect obtained in our model. On the other hand, the new effects that we find should continue to be present. Hence, our analysis does not yield a policy recommendation for governments to perform bailouts, but simply highlights one positive effect of bailouts that has not yet been discussed in the literature.

Empirically, predatory short sales appear to be a rare animal that is difficult to spot. While some market participants claim their existence ${ }^{7}$ the literature does not provide clear positive evidence on the prevalence of manipulative short selling and its effects (e.g Karpoff and Lou, 2010, Shkilko, Van Ness, and Van Ness, 2012, and Boehmer and Wu, 2013). The lack of empirical evidence could be due to the difficulty of distinguishing informed short sellers from uninformed ones. On the other hand, it is also consistent with our results. In our model, predatory short sales are potentially profitable but become less so in the presence of bailouts; for some parameters, the optimal bailout policy completely deters predatory short sales.

\footnotetext{
${ }^{7}$ Examples are statements by the monoline insurer MBIA (2008) or Morgan Stanley CEO John Mack (Thornton, 2008).
} 
Of course, another explanation for the empirical observations is that, contrary to what we and others assume in our models, market conditions are generally such that predatory short selling is not profitable. Even if this were true, our findings would contribute to the policy debate. Governments and regulators continue to implement or consider short selling restrictions. ${ }^{8}$ Our model shows that such restrictions are not necessarily the best instrument for combating negative effects of short selling, even if one does not doubt that short selling can have such effects.

\footnotetext{
${ }^{8} \mathrm{~A}$ recent example is a restriction of short selling activity in shares of two Italian banks, which was approved by the European regulator ESMA in November 2014 (ESMA, 2014).
} 


\section{References}

Acharya, V., I. Drechsler, and P. Schnabl (2015). A pyrrhic victory? -bank bailouts and sovereign credit risk. Journal of Finance 69, 2689-2739.

Acharya, V., I. Gujral, N. Kulkarni, and H. S. Shin (2011). Dividends and bank capital in the financial crisis of 2007-2009.

Acharya, V. and T. Yorulmazer (2007). Too many to fail: an analysis of timeinconsistency in bank closure policies. Journal of Financial Intermediation 16, 1-31.

Bagehot, W. (1873). Lombard Street. Kegan Paul, London.

Bailey, W. and L. Zheng (2013). Banks, bears, and the financial crisis. Journal of Financial Services Research 44, 1-51.

Beber, A. and M. Pagano (2013). Short-selling bans around the world: evidence from the 2007-09 crisis. Journal of Finance 68, 343-381.

Bernanke, B. (2008, Oct, 15). Stabilizing the financial markets and the economy. Speech.

Bernardo, A., E. Talley, and I. Welch (2014, April). Designing corporate bailouts.

Boehmer, E., C. M. Jones, and X. Zhang (2013). Shackling short sellers: The 2008 shorting ban. Review of Financial Studies 26, 1363-1400.

Boehmer, E. and J. J. Wu (2013). Short selling and the price discovery process. Review of Financial Studies 26, 287-322.

Brunnermeier, M. and M. Oehmke (2014). Predatory short selling. Review of Finance 18, 2153-2159.

Chari, V. and P. Kehoe (2013). Bailouts, time inconsistency, and optimal regulation. No. w19192. National Bureau of Economic Research.

Cheng, H. and K. Milbradt (2012). The hazards of debt: rollover freezes, incentives, and bailouts. Review of Financial Studies 25, 1070-1110. 
Cordella, T. and E. L. Yeyati (2003). Bank bailouts: moral hazard vs. value effect. Journal of Financial Intermediation 12, 300-330.

ESMA (2014). Renewal of emergency measure by the italian consob under section 1 of chapter v of regulation no 236/2012 on short selling and certain aspects of credit default swaps.

Faccio, M., R. Masulis, and J. McConnell. (2006). Political connections and corporate bailouts. Journal of Finance 61, 2597-2635.

Farhi, E. and J. Tirole (2012). Collective moral hazard, maturity mismatch, and systemic bailouts. American Economic Review 102, 60-93.

Goldstein, I. and A. Guembel (2008). Manipulation and the allocation role of prices. The Review of Economic Studies 75, 133-164.

Karpoff, J. and X. Lou (2010). Short sellers and financial misconduct. Journal of Finance 65, 1879-1913.

Kyle, A. S. (1985). Continuous auctions and insider trading. Econometrica 53(6), $1315-1336$.

Liu, X. (2010). Predatory short-selling and self-fulfilling crises: when morris-shin meets diamond-dybvig.

Mailath, G. and L. Mester (1994). A positive analysis of bank closure. Journal of Financial Intermediation 3, 272-299.

MBIA (2008, Feb 14). Mbia written testimony.

Miller, E. (1977). Risk, uncertainty and divergence of opinion. Journal of Finance 32, $1151-1168$.

Philippon, T. and P. Schnabl (2011). Informational rents, macroeconomic rents, and efficient bailouts. No. w16727. National Bureau of Economic Research.

SEC (2008). Securities exchange act of 1934 release no. 34-58592. 
Shkilko, A., B. V. Ness, and R. V. Ness (2012). Short selling and intraday price pressures. Financial Management 41-2, 345-370.

Smith, M. (2012). Who gets a lifeline? a political economy of corporate bailouts. APSA 2012 Annual Meeting Paper.

Thornton, E. (2008, Sept 17). Morgan stanley's john mack swings into action. BusinessWeek.com.

Thornton, H. (1802). An enquiry into the nature and effects of the paper credit of Great Britain. Hatchard, London. 


\section{Appendix}

Overview of variables used and their definition:

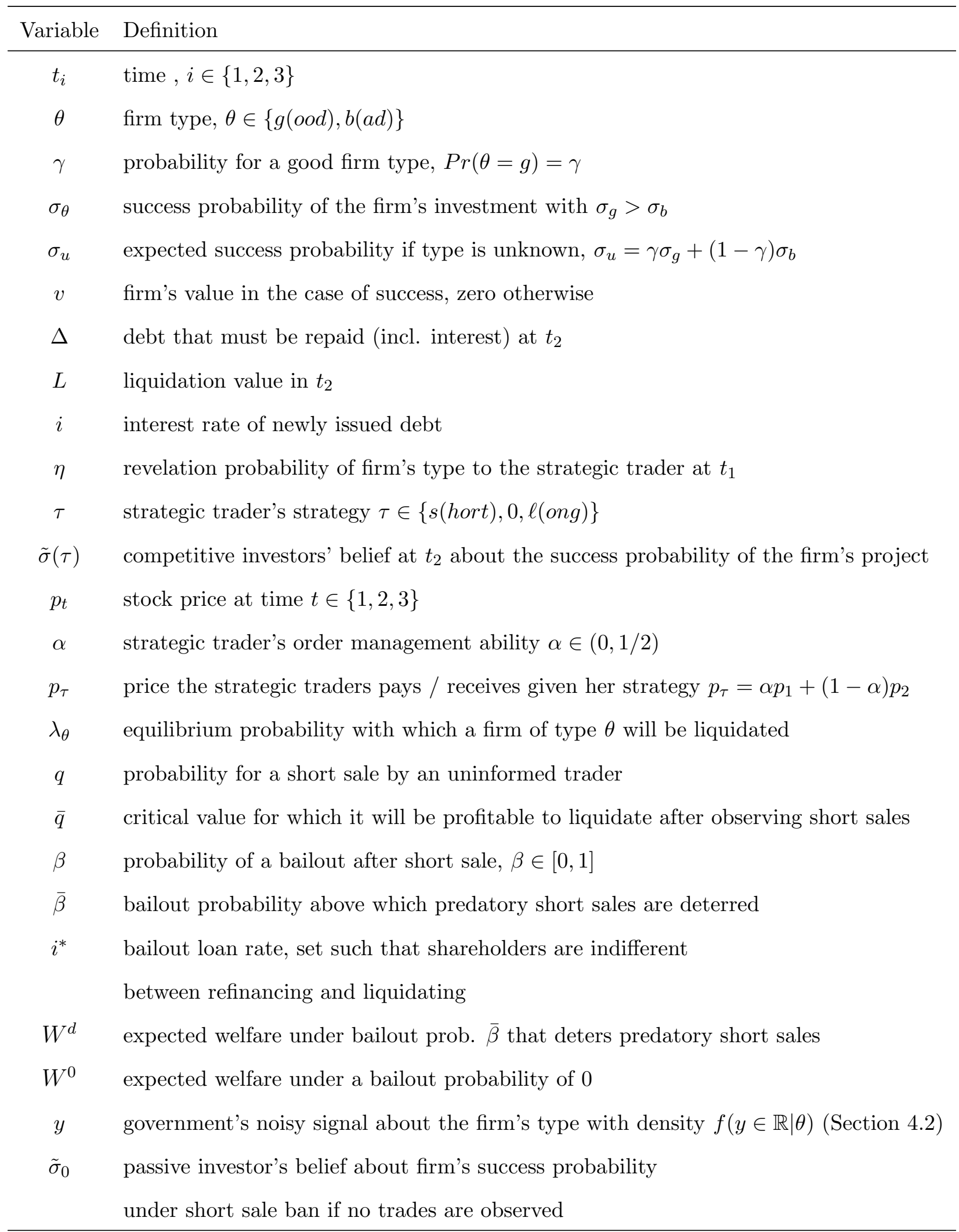



